\title{
EDITORAL
}

\section{O ACESSO LIVRE À INFORMAÇÃO E A CIÊNCIA EM FISIOTERAPIA}

Katia Nunes Sá

Patrícia Lordêlo

As transformações sociais consequentes ao desenvolvimento da internet permitem que a população em geral tenha acesso a muitas informações, muitas vezes sem controle da qualidade de como essa informação foi gerada. Informações incorretas na área da saúde podem oferecer risco de vida aos leitores. ${ }^{[1]}$ Em relação à Fisioterapia, é possível encontrar incontáveis informações sobre modalidades terapêuticas em diferentes sites, youtube e blogs abertos. Entretanto, a informação científica qualificada, com segurança da veracidade das conclusões, ainda permanece, muitas vezes, com o acesso restrito.

Quanto mais qualificada a informação científica na área da Fisioterapia, maior será a tendência de possuir seu acesso limitado. ${ }^{[2]}$ Geralmente será publicada em periódicos estrangeiros (estimulado pelas notas dos programas de acordo com os critérios da CAPES - baixo fator de impacto das revistas em português e necessidade de elevar o índice $H$ dos pesquisadores através de maiores chances de citações), em língua inglesa (porém, nosso país ainda é monoglota) e que exige pagamento para o acesso à informação (nosso país é um país pobre).

Reconhecidos têm sido os esforços feitos pela CAPES (através do Periódicos CAPES), pelo IBICT (através do sistema de editoração eletrônica - SEER) e pelo indexador SCIELO para permitir o acesso a uma maior quantidade de informação científica qualificada. Entretanto, ainda são insuficientes para permitir que seja um acesso amplo e irrestrito à informação na área da Fisioterapia para profissionais técnicos e pesquisadores. ${ }^{[3]}$ Este fato impacta negativamente no desenvolvimento da profissão.

Sabemos que a informação científica é a mola propulsora para o desenvolvimento das ciências em geral. ${ }^{[2]} \mathrm{O}$ conhecimento produzido em instituições de ensino e de pesquisa precisa alcançar o público que pode se beneficiar dos resultados e discussões que são apresentados nos periódicos de cada grande área e de subáreas do conhecimento, através do processo de comunicação científica.

As políticas de acesso livre tem sido defendidas veementemente por pesquisadores, profissionais técnicos, gestores públicos e privados e indivíduos das sociedades contemporâneas em nível mundial. Parece evidente que seja um dos direitos humanos a possibilidade de acesso à informação científica confiável. ${ }^{[4,5]}$

Por outro lado, existe a necessidade de custear o processo de editoração científica, o que vem gerando uma política com adeptos crescentes ao modelo de cobrança dos autores dos artigos científicos para sua publicação. O que também parece um contrassenso. Pesquisadores e financiadores investem muito tempo e dinheiro para que uma pesquisa seja realizada e gere uma informação confiável e para que esta informação chegue ao público alvo ainda se veem obrigados a pagar pela publicação.

Ainda se soma o fato de que um novo mercado econômico se fortalece nos Open Journals e uma publicação pode custar mais de 3.000 euros, o que pode causar impactos negativos sobre a qualidade, 
uma vez que ao pagar, aumentam muito as chances de publicação devido aos conflitos de interesse inerentes à relação fins econômicos versus fins científi$\cos ^{[6]}$ Informações excelentes realizadas por pesquisadores ou instituições com pouco recurso estarão fadadas a uma dificuldade crescente de publicação.

Por este motivo, revistas científicas em Fisioterapia, como a RPF, precisam se fortalecer e receber apoio e reconhecimento, porque existe um grande esforço das instituições que as abrigam em manter o acesso livre, não cobrar dos autores para publicar, contar com o trabalho voluntário dos revisores e editores e sustentar custos com servidor, editora, funcionários, alcançar os crescentes indicadores dos serviços de indexação, entre outros indiretos.

Assim, sugerimos que os leitores aproveitem os artigos que publicamos neste número e estimulamos que os autores que tem seus trabalhos recusados a não desanimar e reestruturar com as recomendações dos revisores e submeter como um novo artigo. Queremos muito contribuir com o desenvolvimento de nossa profissão através de uma ciência qualificada e este canal pode nos ajudar muito neste processo. Aos poucos a RPF se torna mais conhecida, recebe artigos de várias partes do Brasil e prossegue na missão de contribuir com o desenvolvimento da ciência da Fisioterapia em nosso país.

Boa leitura!

Cordialmente,

Editoras Chefes

\section{REFERÊNCIAS}

1. Castro, RCF. Impacto da Internet no fluxo da comunicação científica em saúde. Rev Saúde Pública, 2006;40(N Esp):57-63.

2. Aleluia LR. Comunicação Científica ontem e hoje. Rev Baiana S Pub, 2009;33(1):131-8.

3. Kuramoto, H. Acesso livre à informação científica: novos desafios. LIINC em Revista, 2008;4(2):154-7.

4. Pinheiro, LVR. Do acesso livre à ciência aberta: conceitos e implicações na comunicação científica. RECII, 2014;8(2):153-65.

5. Sena, NK. Open archives: caminho alternativo para a comunicação científica. Ci.Inf. 2000;29(3):71-8.

6. Smith E, Hunt M, Master Z. Authorship ethics in global health research partnerships between researchers from low or middle income countries and high income countries. BMC Med Ethics. 2014 May 28;15:42. doi: 10.1186/14726939-15-42. 